\title{
Three challenges and a rechallenge episode of angio- oedema occurring in treatment with risperidone
}

\author{
B. Kores Plesnicar*, S. Vitorovic, B. Zalar, M. Tomori \\ University Psychiatric Clinic Ljubljana, Studenec 48, 1260 Ljubljana Polje, Slovenia
}

(Received 11 May 2001; accepted 21 August 2001)

Sir: In the literature we found only a few cases of severe cutaneous reactions to the antipsychotic drug risperidone $[2,4]$, either as monotherapy or in combination with other psychotropic drugs, above all with valproate $[1,3]$. Our report describes three occurrences of facial and periorbital oedema with risperidone therapy in one patient that faded away every time the treatment with risperidone was discontinued.

Mrs. R, a 63-year-old patient with chronic paranoid schizophrenia, has been hospitalised in our psychiatric hospital for 36 years. Most of the time her behaviour has been disorganised, with imperative auditory hallucinations, outbursts of severe agitation and physical and verbal aggression. During her long-term hospitalisation, she has been receiving practically all the known antipsychotics as well as clozapine and olanzapine. In 1998 , risperidone $2 \mathrm{mg}$ daily, titrated to $6 \mathrm{mg}$ daily in 2 weeks, was added to fluphenazine, biperiden and bromazepam which, at the time, she had been receiving for many months. Periorbital oedema occurred after 1 month and it faded away in 1 week's time after the cessation of treatment with risperidone. All other drugs remained. Biochemical, haematological and thyroid laboratory values were within normal. Because her psychical status deteriorated and because she did not respond to treatment, 1 year later risperidone titrated to $6 \mathrm{mg}$ daily in 2 weeks was once again introduced into treatment with promethazine, biperiden, clonazepam and nitrazepam. After a 45-day treatment together with risperidone, moderate periorbital and orbital oedema occurred and as a result promethazine was discontinued; the oedema, however, remained unchanged. Five days later risperidone was discontinued (as well) and the oedema faded away within 3 days without any additional treatment. Five months later risperidone $3 \mathrm{mg}$ daily was once again introduced into already existing treatment with fluphenazine, trihexiyphenidyl, lorazepam and nitrazepam. After 3 weeks of risperidone treatment, angio-oedema suddenly occurred and affected the lips, face, neck, tongue and threatening laryngeal potency. Because of a severely swollen tongue and narrowing of her larynx, the patient received intensive anti-allergenic therapy. Risperidone was discontinued immediately. After a few hours, the oedema diminished, breathing became easier; the oedema completely disappeared in 4 days.

Immunologic components were measured only at the last occurrence of angio-oedema. The level of $\mathrm{C} 4$ was reduced to $131 \mathrm{mg} / \mathrm{L}$ (normal range $138-435 \mathrm{mg} / \mathrm{L}$ ) and total classical pathway of activation of complement to $26 \%$ (normal range $72-128 \%$ ). The IgE values were within the normal range. Probability of the type IV allergic reaction was greater than that of the type I. Nevertheless, it could not be ruled out since the courses of type I allergic reaction do not necessarily include the altered $\operatorname{IgE}$ values. Threefold challenge and rechallenge of angio-oedema with risperidone treatment confirm the role of risperidone in the occurrence of angio-

*Correspondence.

E-mail address: blanka.kores@uni-lj.si (B. Kores Plesnicar). 
oedema; however, its mechanism remains elusive. The combination of drugs may be of certain significance - in our case benzodiazepines were already a part of the basic treatment. Further reports on this topic are welcome.

\section{REFERENCES}

1 Baldassano C, Nassir Ghaemi S. Generalized edema with ris- peridone: divalproex sodium treatment [letter]. J Clin Psychiatry $1996 ; 57: 422$.

2 Cooney C, Nagy A. Angio-oedema associated with risperidone [letter]. BMJ 1995; $311: 1204$.

3 Sanders RD, Lehrer DS. Edema associated with addition of risperidone to valproate treatment [letter]. J Clin Psychiatry 1998 ; 59 : 689-90.

4 Terao T, Kojima H, Eto A. Risperidone and allergic reactions [letter]. J Clin Psychiatry 1998 ; 59 : 82-3. 